\title{
PENGORGANISASIAN PEMROSESAN INFORMASI DALAM INGATAN MANUSIA
}

\author{
MUSTAQIM HASAN \\ Institut Agama Islam An Nur Lampung \\ Jl. Ar Rahman No. 04 Desa Sidoharjo kecamatan Jati Agung Kabupaten \\ Lampung Selatan Provinsi Lampung \\ E-mail: mustaqimhasan@an-nur.ac.id
}

\begin{abstract}
Information processing is a sub-study of the field of cognitive psychology. Within the field of cognitive psychology, there has been an attempt to understand the basic mechanisms that govern human thinking. The memory structure has three components: sensory memory, working memory, and long-term memory.

Information processing is closely related to the sources of information that can be obtained through the five senses, the true sense of the word and the intuition of the heart or inspiration. The process of organizing information in memory starts from the process of encoding information followed by storing information, and ending with re-disclosing information that has been stored in memory.

The information processing model targets the individual's ability to process information that can improve and improve his abilities. Information processing refers to methods of collecting/receiving stimuli from the surrounding environment, organizing data, solving problems, finding concepts, and using linguistic and visual symbols.

And the application of information processing in learning can be done in a way that teachers can create interesting learning topics to attract students' attention, and teachers can help students remember the subjects being taught. more effective if students have a great interest and a strong desire to repeat what they have learned.
\end{abstract}

Keywords: Organizing Information Processing, Human Memory

\begin{abstract}
ABSTRAK
Pengolahan informasi merupakan sub kajian dari bidang studi psikologi kognitif. Dalam bidang psikologi kognitif, ada upaya untuk memahami mekanisme dasar yang mengatur pemikiran manusia. Struktur memori memiliki tiga komponen: memori sensorik, memori kerja, dan memori jangka panjang.
\end{abstract}


Pengolahan informasi erat kaitannya dengan sumber informasi yang di dapat melalui panca indra, akal berita yang benar dan intuisi hati atau ilham. Proses pengorganisasian informasi dalam ingatan dimulai dari proses penyandian informasi diikuti dengan penyimpanan informasi, dan diakhiri dengan mengungkapkan kembali informasi-informasi yang telah disimpan dalam ingatan

Model pengolahan informasi menargetkan pada kemampuan individu dalam mengolah informasi yang dapat meningkatkan dan memperbaiki kemampuannya. Pengolahan informasi mengacu pada metode mengumpulkan/menerima rangsangan dari lingkungan sekitar, mengorganisasikan data, memecahkan masalah, menemukan konsep, dan menggunakan simbol linguistik dan visual.

Dan penerapan pengolahan informasi dalam pembelajaran dapat dilakukan dengan cara guru dapat membuat topik pembelajaran yang menarik untuk menarik perhatian siswa, dan guru dapat membantu siswa mengingat mata pelajaran yang diajarkan. lebih efektif jika siswa memiliki minat yang besar dan keinginan yang kuat untuk mengulang apa yang telah dipelajarinya.

Kata kunci: Pengorganisasian Pemrosesan Informasi, Ingtan Manusia

\section{PENDAHULUAN}

Manusia disebut sebagai makhluk paling sempurna dibandingkan dengan ciptaan Tuhan Yang lainnya. Di sebut makhluk sempurna karena manusia dikaruniai fisik yang bagus akal dan fikiran sebagai modalitas utama dalam proses berpikir dan berperilaku dan hati nurani sebagai pusat kendali dari perasaan manusia dan hampir semua hal yang tidak dimiliki makhluk lainnya.

Kemampuan mengingat pada manusia memiliki fungsi penting dalam kehidupan manusia, terutama untuk memecahkan masalah yang kita hadapi sehari-hari. Ketika manusia melakukan aktivitas berpikir dan bernalar, kebanyakan manusia menggunakan fakta dari kemampuannya untuk mengingatnya. Manusia menggunakan konsep waktu dengan menghubungkan masa kini dan masa lalu serta merencanakan masa depan. Hal ini dimungkinkan dengan adanya fitur memori yang kuat yang dapat beradaptasi dengan situasi yang berbeda. Karena kemampuan mengingat manusia ini, bisa dikatakan sebagai makhluk bersejarah. Ini berarti makhluk yang tumbuh dalam sejarah masa lalu yang tidak 
ditentukan oleh pengaruh proses apa yang terjadi sekarang, tetapi masih ada dan dapat hidupkan kapan saja.

Al-Quran menggambarkan dengan jelas fenomena pada diri manusia:

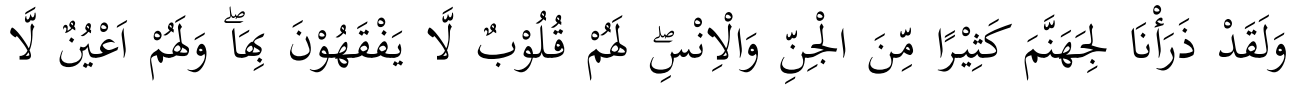

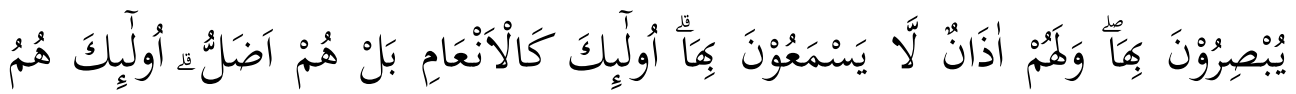
الْغْفِلْونَنَ

Artinya : Dan Sesungguhnya Kami jadikan untuk (isi neraka Jahannam) kebanyakan dari jin dan manusia, mereka mempunyai hati, tetapi tidak dipergunakannya untuk memahami (ayat-ayat Allah) dan mereka mempunyai mata (tetapi) Dia tidak menggunakan untuk melihat (tanda kekuasaan Allah), dan mereka (tetapi) memiliki telinga yang tidak dia gunakan untuk mendengar (tanda Allah). Mereka seperti sapi dan bahkan lebih tersesat. Mereka adalah orang-orang yang malas. (Al A'raf : 179) $^{1}$

Kemampuan manusia untuk mengingat sesuatu disebut dengan memory atau ingatan. Perdebatan tentang ingatan manusia akan sangat menarik mengingat fungsinya yang sangat penting dalam kehidupan manusia.

Manusia perlu mengoptimalkan potensi fitrah manusia untuk dapat mengaktualisasikan diri dalam kehidupan dengan cara belajar segala sesuai yang ada di sekitar lingkunganya. Belajar merupakan kegiatan yang kompleks. belajar adalah seperangkat kognitif yang mengubah sifat stimulasi lingkungan melalui pengolahan informasi, menjadi kapabilitas baru. ${ }^{2}$

Belajar terutama ditentukan oleh organisasi informasi dalam ingatan manusia. Seperti yang kita ketahui, memori sangat penting dalam kehidupan manusia.

Berdasarkan uraian tersebut penulis tertarik untuk menuangkan dalam sebuah harya tulis judul "Pengorganisasian Ilmu Pengetahuan dalam Ingatan Manusia Prespektif Islam".

${ }^{1}$ Depag RI, Al Quran dan Terjemahnya, (Bandung, CV Diponegoro, 2009) hlm. 138

2 Abuddin Nata, Perspektif Islam Tentang Strategi Pembelajaran, (Jakarta, Prenadamedia Group) Cet ke 3, Maret 2014, hlm. 96 


\section{METODE PENULISAN}

Penyusunan karya tulis ini menggunakan penelitian library research yaitu penelitian yang di lakukan di perpustakaan untuk mengumpulkan dan menganalisis data dari perpustakaan. Baik dalam bentuk buku, jurnal ilmiah yang diterbitkan secara berkala, cerita sejarah, dokumen, dan bahan pustaka lainnya, dapat digunakan sebagai sumber referensi untuk menyusun laporan karya penelitian ilmiah.

Sumber data berasal dari literatur yang berkaitan dengan penelitian yang dibahas, baik berupa buku referensi, hasil penelitian, maupun jurnal ilmiah. Metode pengumpulan data adalah pencarian dokumen dari sumber terbaru yang relevan dan bibliografi. Teknik analisis kegiatan analisis data model ini antara lain: reduksi data, penyajian data, dan penarikan/validasi kesimpulan. Data yang diperoleh dilakukan analisis isi tema untuk menemukan jawaban (solusi) yang tepat.

\section{PEMBAHASAN}

\section{A. Pengorganisasian Informasi Dan Pengetahuan}

Pengorganisasian pengetahuan dapat dikatakan sebagai kegiatan penataan yang sengaja dilakukan sebagai upaya untuk memperoleh informasi. Informasi yang masuk kemudian diproses dan tersimpan berkaitan erat dengan kemampuan kognisi seseorang. Dengan kata lain, pemrosesan informasi dipengaruhi oleh memori dan faktor kognitif, termasuk kecerdasan seseorang. ${ }^{3}$ Model pengolahan informasi ini didasarkan pada teori belajar kognitif (Piaget) dan berorientasi pada kemampuan siswa dalam mengolah informasi yang dapat meningkatkan kemampuannya. Pengolahan informasi mengacu pada cara mengumpulkan/menerima rangsangan dari lingkungan, mengorganisasikan data, memecahkan masalah, menemukan konsep, dan menggunakan simbol verbal dan visual. Ilmu kognitif adalah studi tentang kecerdasan manusia, program komputer, dan teori abstrak dengan penekanan pada perilaku cerdas, seperti komputasi. ${ }^{4}$

Dengan adanya pengorganisasian informasi, individu dapat terbantu untuk menyimpan, menorganisasi, dan mengungkapkan kembali informasi tersebut. Model pemrosesan informasi ini sering pula disebut model kognitif information processing disajikan melalui skema yang dikutip berikut ini.

\footnotetext{
${ }^{3}$ Frishammar, J, Characteristics in Information Processing Approaches, International. Journal of Information Management, 2002,hlm.143

${ }_{4}$ Aminah Rehalat, Model Pembelajaran Pemrosesan Informasi, JPIS, Jurnal Pendidikan Ilmu Sosial, Volume 23, No. 2, Edisi Desember 2014, hlm. 5
} 
Model belajar pemrosesan informasi yang di kemukkakan Anita E. Woolfolk ini sering pula disebut model kognitif information processing, karena dalam proses belajar ini tersedia tiga taraf struktural sistem informasi, yaitu:

1. Sensory atau intake register: informasi masuk ke sistem melalui sensory register, tetapi hanya disimpan untuk periode waktu terbatas. Agar tetap dalam sistem, informasi masuk ke working memory yang digabungkan dengan informasi di long-term memory.

2. Working memory: Pemrosesan atau manipulasi informasi dilakukan dalam memori kerja, di mana pemikiran sadar terjadi. Kerugian dari memori kerja adalah memiliki jumlah konten yang sangat terbatas dan pada saat yang sama memperhatikan sejumlah kecil informasi..

3. Long-term memory, Ini dapat menampung semua informasi yang sudah dimiliki siswa, karena kapasitas kontennya bisa tidak terbatas. Kelemahannya adalah betapa sulitnya mengakses informasi yang tersimpan di sana. ${ }^{5}$

\section{B. Sumber Informasi Dan Pengetahuan}

Dalam dunia islam diakui ada empat saluran utama yang dapat dijadikan sebagi sumber ilmu pengetahuan yaitu panca indra (al haws al khams), akal (al aql), berita yang benar (al khabar ash shodiq) dan intuisi hati atau ilham. Secar rinci, sumber sumber ilmu tersebut diuraikan sebagi berikut: 6

\section{Panca Indra}

Panca indera (al-hawas al-khams) berarti pendengaran (assam'), penglihatan (al-bashar), penciuman (asy-syamm), rasa (azzauq), dan sentuhan. Atau sentuhan (al-lams) (ash-Shirazi, tt: 2). Ada lagi sensasi keenam yang disebut al-hiss al-musya tarak atau akal sehat. Ini termasuk ingatan atau ingatan (adh-dzakirah) atau imajinasi atau perkiraan (al-wahm).

2. Akal

Sebagai sumber ilmu, akal melakukan nalar atau pikir dalam proses pencarian ilmu. Dalam al-Qur`an, selain kata akal (al-,,aql) dengan berbagai derivasinya, untuk mengungkapkan "perbuatan berpikir", ditemukan kata nazhara, yang secara abstrak dalam arti berpikir dan merenungkan, juga kata tadabbara, yang berarti merenungkan, kata tafakkara yang berarti berpikir, kemudian ada kata tadzakkara, yang berarti mengingat, mendapat pelajaran,

${ }^{5}$ Woolfolk, Anita, Educational psychology, (Boston: Pearson) 2007, hlm. 197

${ }^{6}$ Duski Ibrahim, Bangunan Ilmu Dalam Islam, (Palembang, Karya Sukses Mandiri), Cet Ke 1, Agustus 2015, Hlm. 27-32 
memperhatikan, selanjutnya ada kata fahima yang berarti memahami atau mengerti.

3. Intuisi Hati (qalb) atau Ilham.

Pengetahun seseorang terkadang didapatkannya melalui intuisi hati (qalb) atau ilham. Intuisi atau ilham merupakan sumber ilmu bersifat batin yang berkaitan dengan hati dan jiwa seseorang dalam memberikan sesuatu pengetahuan. Dengan intuisi hati (qalb) atau ilham, seseorang dapat menangkap pesan-pesan ghaib, isyaratisyarat ilahi, menerima ilham, al-fath, kasyf, dan sebagainya..

\section{Informasi Yang Benar/Al-Khabar ash-Shadiq}

Al-khabar ash-shadiq diartikan informasi yang benar. Informasi yang benar adalah suatu informasi yang berasal dari dan bersandar pada otoritas tertentu. Dalam masalah agama, sumber informasi ini berasal dari wahyu, baik yang ditilawatkan (kitab suci) maupun yang tidak ditilawatkan (Sunnah Nabi), kemudian disampaikan kepada pihak-pihak yang berkepentingan.

\section{Memori Perspektif Psikologi Komunikasi}

Menurut ahli psikologi, dalam sistem ingatan memerlukan tiga hal, yakni: memberi kode (encoding), menyimpan (storage), dan mengeluarkan atau mengingat kembali (retrieval). ${ }^{7}$ Istilah yang lain yang sering digunakan yaitu: memasukkan (learning), menyimpan (retention), dan menimbulkan kembali (remembering). ${ }^{8}$

1. Penyusunan kode (encoding)

Pada tahap ini, pesan dari gejala fisik diterjemahkan menjadi semacam kode yang dapat diterima dalam memori. Beberapa kenangan yang dikenang adalah kenangan yang pernah dialami seseorang. Orang yang berpengalaman dapat dibagi menjadi 1) disengaja dan 2) tidak disengaja.

2. Penyimpanan (storage)

Pada tahap ini informasi yang telah diterima dan diseleksi untuk disimpan ke dalam daftar (sensory register) dan jejak memori (memory traches) agar dapat dipanggil kembali apabila diperlukan. Dalam tahap ini terjadi proses pemeliharaan stimulus/imput di dalam sistem memori otak.

3. Mengingat kembali (retieval)

Tahap ini merupakan tahap dimana diinginkan untuk dapat mengingat dan menggunakan informasi yang tersimpan ketika

\footnotetext{
${ }^{7}$ Bimo Walgito, Pengantar Psikologi Umum, (Yogyakarata: ANDI, 2004), hlm. 145.

8 Akyas Azhary, Psikologi Umum Dan Perkembangan, (Bandumg: Mizan Media Utama, 2004), hlm. 99.
} 
seseorang membutuhkan pembentukan dan hasil pengolahan dan penyimpanan informasi dalam sistem memori otak. Jika proses pemanggilan ini gagal, proses yang disebut "lupa" terjadi.

\section{Mekanisme Memori} berikut: ${ }^{9}$

Cara kerja memori dapat diterangkan dengan teori sebagai

a) Teori Aus (Disuse Theory). Menurut teori ini memori hilang atau memudar karena waktu. Seperti halnya otot manusia, bila dilatih terusmenerus, maka memori akan kuat.

b) Teori Inferensi (Inference theory). Menurut teori ini, memori adalah meja lilin atau kanvas. Pengalamannya adalah melukis di atas meja lilin atau kanvas. Misalnya, cobalah menggambar teori di kanvas pertama dan kemudian segera merekam teori lain. Rekaman yang kedua akan menyebabkan terhapusnya rekaman yang pertama atau mengaburkannya. Dalam teori ini terdapat variabel yang mempengaruhi, yang pertama adalah inhibisi retroaktif (hambatan ke belakang).

c) Teori pengolahan informasi (information processing). Menururt teori ini, manusia merupakan makhluk yang mengolah informasi. Teori ini diadaptasi dari konsep ilmu informatika

\section{Timbulnya Ingatan}

Ingatan timbul dalam berbagai jenis:

a) Ingatan kepada sesuatu, seperti nama orang tercantik di suatu kelas. Di sini yang ingin direproduksikan hanya sebahagian ingatan itu. Hal itu dilakukan juga pada waktu ujian yang menggunakan metode esei.

b) Rekoleksi, yaitu mengingat kembali sebuah peristiwa masa lampau secara lengkap, seperti yang dilakukan oleh seorang tertuduh yang menjawab semua pertanyaan dari hakim atas semua perilakunya dala kejahatan yang telah dilakukannya.

c) Rekognisi, yaitu mengenal kembali sesuatu hal, benda atau orang setelah sebahagian dari padanya kelihatan atau kedengaran kembali, seperti melihat seorang anak teringat kembali kepada bapaknya; karena anak tersebut serupa benar dengan bapaknya.

d) Mempelajari kembali sesuatu, untuk memperlihatkan bahwa ada sisa ingatan yang tinggal biarpun telah lama sesuatu it dipelajari.

e) Menggali kesadaran rentang ingatan.

${ }^{9}$ R. Funny Mustikasari Elita, Memahami Proses Memori, Jurnal Mediator, Vol. 1485 No.1 


\section{Faktor Penyebab Lupa}

Memori mungkin tidak berfungsi: lupakan. Apa yang membuat orang lupa? Atau melupakan sesuatu? Terkadang lupa adalah mekanisme psikologis untuk menghadapi hidup yang berlangsung setiap hari. Namun ketika kita telusuri, ada beberapa alasan orang lupa.

a) Merosot karena tidak terpakai, Ada asumsi yang sudah lama yang mengatakan bahwa belajar meninggalkan jejaknya dalam otak berupa perubahan fisik yang sebelumnya tidak ada di sana. Dengan berlalunya waktu, proses yang berlaku dalam otak mengakibatkan jejakjejaknya makin terkikis yang menyebabkan mundurnya daya mengingat.

b) Gangguan. Untuk mempelajari materi baru, memori materi lama agak terganggu. Instruktur komunikasi yang akrab dengan istilah ilmu komunikasi merasa semakin lupa dengan istilah komunikasi ketika mengingat nama-nama mahasiswa baru. Oleh karena itu, dia tidak mencoba untuk menghafal nama mahasiswa barunya lagi. Di sisi lain, beberapa orang terhalang untuk mempelajari sesuatu yang baru karena materi lama yang telah mereka pelajari.

c) Represi :Pengalaman masa lalu yang sengaja dipendam kuat-kuat agar tidak dikenang. Misalnya, merasa bersalah atas pembunuhan karakter yang dilakukan oleh seseorang yang tidak tahu apa-apa selain dirinya sendiri dan Tuhan. Terlepas dari kebebasannya, tindakannya tidak dapat disangkal dan rasa bersalah sangat ditekan. Pada akhirnya, rasa bersalah meremas jiwanya, dan dia meminta maaf kepada mereka yang menyakiti emosinya.

d) Penyaringan. Untuk memberi gambaran tentang proses ingatan, telah disusun satu teori oleh D.E. Brent yang dinamai Teori Saringan. Satu peristiwa, seperti pencurian di layar kaca menyampaikan kesan-kesanya kepada penonton melalui mata dan kadangkadang juga telinganya. Semua kesan itu masuk ke dalam suatu tempat penyimpan jangka pendek. Disini banyak kesankesan itu hilang, tidak banyak lagi yang tinggal tanpa diproses terlebih dahulu. Pengolahan itu tidak sembarangan saja, tetapi diarahkan oleh sebuah saringan yang mengistimewakan sebahagian yang lain kesan-kesan itu dari pada sisanya. Saringan tidak membebani memori. Hanya bagian relevan yang diproses yang dipilih dari tayangan ini. Tayangan yang difilter hanya dimasukkan untuk penghematan jangka panjang. 
Menurut Ebbinghaus ada anggapan dari beberapa ahli tentang proses ingatan, bahwa di balik proses itu ada satu ide tentang mekanik kehidupan jiwa dalam bentuk asosiasi dari pusat rangsangan dari kulit otak yang ada. Asosiasi ini dikenal semenjak Aristoteles, sebagai prinsipprinsip gangguan antara ruang dan waktu, artinya apa yang dipelajari pada waktu dan tempat yang bersamaan akan terikat menjadi satu untuk sementara waktu. Tanggapan yang timbul bersamaan dalam kesadaran mempunyai kecenderungan untuk memproduksikan satu sama lain. ${ }^{10}$

\section{Aplikasi Pengolahan Informasi dalam Pembelajaran}

Pengolahan informasi terkait dengan proses pembelajaran. Pengolahan informasi adalah kemampuan mental atau spiritual yang berupa mengamati, melihat, mengharapkan, memperhatikan, berpikir, berpikir, dan mengevaluasi. Selama belajar mandiri, ada tiga proses yang hampir bersamaan: perolehan informasi baru, transformasi, dan pengujian relevansi dan akurasi pengetahuan. ${ }^{11}$

Belajar menurut Ausubel (1961) ada empat macam tipe belajar yakni:

1. belajar dengan menerima saja (reception learning): si pelajar hanya menyerap bahan-bahan yang tersedia baginya sehingga di masa yang akan datang ia bisa memproduksi kembali.

2. Belajar dengan menemukan seseuatu (discovery learning): si pelajar menemukan sendiri materi yang harus dipelajari. Ia tidak hanya menyerap, tetapi mengorganisasi dan mengintegrasikan materimateri yang dipelajarinya ke dalam struktur kognitifnya. Pengulangan dari discovery learning meningkatkan kemampuan penemuan dari individu yang bersangkutan.

3. Belajar dengan menghafal (rote learning): si pelajar mengingat-ingat bahan yang dipelajari secara verbatim, yaitu sebagai rangkaian katakata.

4. Belajar dengan mengartikan (meaningful learning): Siswa berada dalam situasi yang paling tidak mencakup dua sifat. Artinya, (a) materi yang akan dipelajari memiliki makna potensial. (B) Pembelajar sudah cenderung mempertimbangkan untuk mengasosiasikan informasi dan konsep baru dengan struktur kognitif relevan yang ada.

Dari penjelasan di atas, jelaslah bahwa learning by acceptance juga biasa disebut dengan learning by hafalan. Di sisi lain, belajar

${ }^{10}$ Ibid. Hlm. 155

${ }^{11}$ Dahar, Ratna Wilis,Teori - teori Belajar. (Jakarta. Erlangga, 1989.) hlm. 92 
dengan penemuan adalah belajar dengan menafsirkan. Jika ada belajar dengan menemukan sesuatu yang jatuh ke dalam memori, itu adalah belajar dengan coba-coba (trial and error learning). Di sisi lain, ketika belajar dengan penemuan dikategorikan sebagai makna, itu adalah belajar yang menggunakan wawasan (pemecahan masalah yang berwawasan).

Aplikasi pengolahan informasi dalam proses pembelajaran dapat ditekankan dengan cara sebagai berikut:

1. guru membimbing para peserta didik dalam penerimaan stimulus dengan cara bagaimana membuat topik pembelajaran yang menarik bagi peserta didik agar menjadi perhatian peserta didik

2. guru menyusun metode pembelajaran yang membuat peserta didik lebih mudah mengingat materi pelajaran yang diajarkan, misalnya menggunakan gambar visual, grafik, kode-kode atau singkatansingkatan yang dapat mempermudah peserta didik dalam menyimpan materi pelajaran di dalam ingatan mereka.

3. Meningkatkan motivasi belajar peserta didik karena mengingat akan lebih efektif apabila peserta didik memiliki minat yang besar dan motivasi yang kuat untuk mengulang kembali materi pelajaran yang sudah dipelajari.

\section{SIMPULAN}

Pengorganisasian pengetahuan adalah aktivitas penataan yang disengaja untuk memperoleh informasi. Informasi yang masuk kemudian diproses dan disimpan erat kaitannya dengan kemampuan kognitif Anda. Struktur memori memiliki tiga komponen: memori sensorik, memori kerja, dan memori jangka panjang.

Pengolahan informasi erat kaitannya dengan sumber informasi yang di dapat melalui panca indra (al haws al khams), akal (al aql), berita yang benar (al khabar ash shodiq) dan intuisi hati atau ilham. Proses pengorganisasian informasi dalam ingatan dimulai dari proses penyandian informasi (encoding), diikuti dengan penyimpanan informasi (storage), dan diakhiri dengan mengungkapkan kembali informasi-informasi yang telah disimpan dalam ingatan (retrieval).

Memori merupakan selayaknya yang harus diperhatikan, khususnya dalam ilmu komunikasi. Komunikasi harus dapat membaca jumlah memori yang digunakan seseorang dan perkiraan isi memori orang tersebut. Secara khusus, kita jarang mengetahui kemampuan memori seseorang yang tidak kita kenal. 
Pengolahan informasi mengacu pada metode mengumpulkan/menerima rangsangan dari lingkungan, mengorganisasikan data, memecahkan masalah, menemukan konsep, dan menggunakan simbol linguistik dan visual.

\section{REFERENSI}

Abuddin Nata, Perspektif Islam Tentang Strategi Pembelajaran, (Jakarta, Prenadamedia Group) Cet ke 3, Maret 2014

Akyas Azhary, Psikologi Umum Dan Perkembangan, (Bandumg: Mizan Media Utama, 2004

Aminah Rehalat,"Model Pembelajaran Pemrosesan Informasi", JPIS, Jurnal. Pendidikan Ilmu Sosial , Volume 23, No. 2, Edisi Desember 2014

Bimo Walgito, Pengantar Psikologi Umum, (Yogyakarata: ANDI, 2004)

Dahar, Ratna Wilis,Teori - teori Belajar. (Jakarta. Erlangga, 1989.)

Depag RI, Al Quran dan Terjemahnya, (Bandung, CV Diponegoro, 2009)

Duski Ibrahim, Bangunan Ilmu Dalam Islam, (Palembang, Karya Sukses Mandiri

Woolfolk, Anita, Educational psychology, (Boston: Pearson) 2007

Frishammar, J, Characteristics in Information Processing Approaches. International. Journal of Information Management , 2002

R. Funny Mustikasari Elita, Memahami Proses Memori, Jurnal Mediator, Vol. 1485 No.1 2004 